\title{
Let's talk about the notion of cure
}

\author{
Amy Robertson describes how language around cure has shaped her understanding of wellness \\ and the importance of seeing bodies with chronic conditions as resilient
}

\author{
Amy D Robertson
}

I first encountered the notion of cure as a little girl. I received a diagnosis of arthritis at the age of 2 and remission was a central part of conversations about my condition. Although I cannot recite the specifics, I distinctly remember the energy of those conversations. There was so much hopefulness that hinged on my going into remission, so much relief when it seemed that I had, and such deep sadness when my arthritis "came back.” I took all of it in: the hope and the despair, the powerful notion that remission was the key to my wellness, and ultimately the sense that I was fundamentally broken and unwell.

\section{Cure as an experience}

Curehas been communicated to me across my lifetime in two salient ways. Health professionals often communicate to me a "best case scenario" in which I will heal from each of my chronic medical conditions. The "next best thing" is that I would have as few symptoms, or get as close to normal, as possible. Cure, as an experience, is about hoping to become normal, and it is achieved through medical intervention.

What I internalised from a lifetime of conversations like these is that my body is broken and I will likely never be well. "Cure" and "normal" have projected impossible standards onto my body. And the narratives of brokenness and unwellness that I internalised have had painful consequences for me: chronic anxiety about my health, a negative self image, and a lack of agency around my wellness.

\section{Extraordinary and resilient bodies}

Fortunately, I have been on a journey to heal my relationship to my body. Here, I invite you to be a part of this healing for patients like me, by asking you to consider the following re-framings: bodies with chronic medical conditions are extraordinarybodies, resilient bodies, bodies deeply committed to healing themselves again and again with support. Wellness is more about one's experience of life and investment in oneself than about external standards or sets of circumstances.

Health professionals can actualise these framings by using their expertise to help patients achieve their own wellness goals. They can ask patientsto identify goals and work with them to identify care that meets their goals. They can narrate patients' bodies as resilient, help patients to remember and tap into their own healing potential, and avoid using language such as "normal" or "functional."

I recognise that I am asking you to do something that is in my experience counter-cultural. After all, not all bodies heal themselves, even with the support of medical technology. Indeed, this latter critique emerges from a vision of healing that centres around returning to a state of minimal symptoms and maximal functionality, as defined against an external norm. I am inviting you to participate in a different vision, in which healing is about thriving within one's life as it is, where medical professionals support that thriving with their expertise rather than defineit for us.

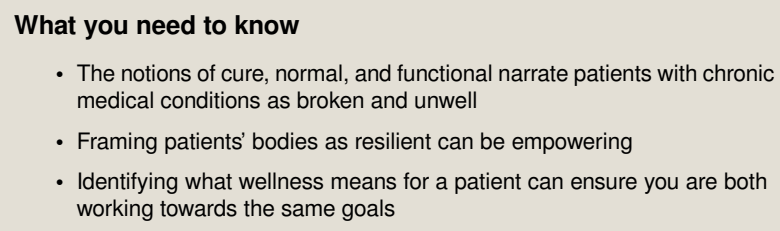

I thank Kelly Moyaert, Liza Ziliak, and authors Eli Clare and Matthew Sanford for the ways in which they have shaped my thinking about cure.

\section{Competing interests: none.}

Provenance and peer review: Commissioned, based on an idea from the author: not externally peer reviewed.

Published by the BMJ Publishing Group Limited. For permission to use (where not already granted under a licence) please go to http://group.bmj.com/group/rights-licensing/ permissions 
